\title{
Indonesia's NDC bodes ill for the Paris Agreement
}

To the Editor - The Paris Agreement on climate change seeks to keep the increase in global temperature below $2^{\circ} \mathrm{C}$ by 2100 , with further efforts to limit the increase to $1.5^{\circ} \mathrm{C}$. However, the nationally determined contributions (NDCs) submitted by the Parties to the UNFCCC have been estimated to imply a global warming of $2.6-3.1^{\circ} \mathrm{C}$ (ref. ${ }^{1}$ ). The Agreement also states that targets for the reduction of emissions should be strengthened over time. This strengthening would obviously be required to achieve even the $2{ }^{\circ} \mathrm{C}$ target, meaning that all Parties would need to both deliver on their initial commitments and go beyond them.

A reduction in emissions from changes in land use is important for achieving the goal of the Agreement ${ }^{2}$. Indonesia's emissions from land-use change are among the three highest national estimates ${ }^{2}$, and it is ranked as the eighth highest global emitter over all sources ${ }^{3}$. It appeared to pledge an 'unconditional reduction target of $29 \%$ and conditional reduction target up to $41 \%$ of the business-as-usual scenario by $2030^{\prime}$ in its NDC ${ }^{4}$. However, in Table 1 of the Indonesian NDC - which presents the breakdown of the sectoral contributions to emissions reductions - the total reduction in emissions amounts to $38 \%$ by 2030 (29\% unconditional and $9 \%$ conditional). A reduction of $38 \%$ could be regarded as technically consistent with the stated reduction target of 'up to' $41 \%$, but it seems contradictory for the main body of the NDC to present a commitment that is noted by the international community ${ }^{2,5}$ and immediately watered down in a little-noticed accompanying table.

Countries are required to report to the UNFCCC at regular intervals to provide updates on their progress towards delivering on their commitments. The inconsistency about the emissions reduction target noted above is repeated in Indonesia's most recent national communication": "The emission reduction target is set at $29 \%$ of the reference emission level by 2030 with an unconditional target and up to $41 \%$ with international support (conditional target)." However, it goes on to state: "GHG emission reduction targets by 2020 in accordance with the Presidential Regulation No. $61 / 2011$ are $26 \%$ (unconditional) and $41 \%$ (conditional) below the national baseline emission level, while by 2030 it is targeted at $29 \%$ (unconditional) and $38 \%$

(conditional; Table 5.4)."

This inconsistency, present both in Indonesia's NDC and the Third National Communication, highlights the importance of the review process in ensuring transparency of action and support under the Paris Agreement ${ }^{7}$. The fact that such an important detail had gone unnoticed before now also raises the question of whether it is only the Indonesian NDC and national communication that make contradicting statements about intended contributions, or whether other countries have submitted NDCs and communications that have similar problems. To ensure transparency and accountability ${ }^{8}$, all of the NDCs and national communications should be reviewed immediately and the results made available to the international community.

Finally, and most importantly, Indonesia's approach (promising a certain reduction in emissions but then planning to deliver 3\% less) bodes ill for the Paris Agreement's capacity to deliver on its aim if other countries follow suit in scaling back their commitments rather than ramping them up.

\section{Luca Tacconi}

Crawford School of Public Policy, Australian National University, Canberra, Australian Capital Territory, Australia.

e-mail:luca.tacconi@anu.edu.au

Published online: 28 September 2018

https://doi.org/10.1038/s41558-018-0277-8

\section{References}

1. Rogelj, J. et al. Nature 534, 631-639 (2016).

2. Grassi, G. et al. Nat. Clim. Change 7, 220-226 (2017).

3. CAIT Climate Data Explorer (World Resources Institute; accessed 28 June 2018); http://cait.wri.org.

4. First Nationally Determined Contribution (Republic of Indonesia, 2016).

5. CAIT Paris Contributions Map: Indonesia (World Resources Institute,2017); http://cait.wri.org/indc/\#/profile/Indonesia.

6. Third National Communication Under the United Nations Framework Convention on Climate Change (Republic of Indonesia, 2017).

7. Winkler, H. et al. Clim. Policy 17, 853-872 (2017).

8. Karlsson-Vinkhuyzen, S. I. et al. Clim. Policy 18, 593-599 (2018).

\section{Acknowledgements}

I would like to acknowledge the participants of a seminar presented at The World Bank, Washington, on 18 July 2018. 